\title{
Responding to Migrant and Refugee Healthcare Needs in Ireland
}

\author{
Evelyn Fennelly ${ }^{1}$, Gerard T. Flaherty ${ }^{1,2^{*}}$ \\ ${ }^{1}$ School of Medicine, National University of Ireland, Galway, Ireland \\ ${ }^{2}$ School of Medicine, International Medical University, Kuala Lumpur, Malaysia
}

Corresponding Author: Gerard T. Flaherty, MD, Professor of Medical Education, School of Medicine, National University of Ireland, Galway, Ireland. Tel: +35391495469, Email: gerard.flaherty@ nuigalway.ie

Received September 7, 2016; Accepted October 3, 2016; Online Published February 19, 2017

\begin{abstract}
Human migration, both voluntary and precipitated by conflict and persecution, continues to pose challenges to the healthcare infrastructure of host countries. The scale of international migration to Ireland has increased substantially in recent years. Both economic migrants and refugees have complex health needs including those related to infectious diseases, malnourishment, gender-specific issues, cultural adaptation, and mental health. While all refugees are highly vulnerable to physical trauma and illness, this vulnerability is heightened for women and children. Linguistically and culturally accessible care for migrants is essential in developing trust in and respect for Western medicine. Integration of migrants and multiculturalism as a national policy has many benefits for the health of incoming migrants and society in general.

Keywords: Migrants, Refugees, Medicine, Travel
\end{abstract}

Citation: Fennelly E, Flaherty GT. Responding to migrant and refugee healthcare needs in Ireland. Int J Travel Med Glob Health. 2017;5(1):1-4. doi:10.15171/ijtmgh.2017.01.

\section{Introduction}

The number of international migrants residing in the Republic of Ireland has increased substantially, from 350600 in 2000 to 746300 in $2015 .{ }^{1}$ This reflects a worldwide trend of increasing migration. ${ }^{2,3}$ Migrants have a number of specific health needs. The growth in the number of migrant residents in Ireland poses challenges for health services which require adaptation and creative solutions.

The terms "asylum seeker," "refugee," and "migrant" can be confusing. The 1951 Refugee Convention on the Status of Refugees defines asylum seekers as those fleeing persecution or conflict and therefore seeking international protection. A refugee is an asylum seeker whose claim has been approved, though some migrants fleeing war or persecution are considered by the United Nations (UN) to be refugees before they receive asylum and may enjoy prima facie refugee status. An economic migrant is someone whose primary motivation for leaving their home country is improved employment opportunities and economic gain. The term "migrant" is generally accepted as an umbrella term to encompass these three groups. For ease of discussion, the term "refugee" as used in this perspective article embraces asylum seekers and refugees. This essay explores the health needs specific to refugees and to economic migrants as well as the health needs common to migrants in general.

The majority of migrants traverse international borders in search of better economic and social opportunities. ${ }^{3}$ Other migrants are forced to flee their native countries by war, economic, political, cultural, or environmental conditions. Migrants may experience immediate and lifelong health repercussions because of moving across borders. ${ }^{4}$ Ireland is currently experiencing a mixed-migration phenomenon, where economic migrants and refugees are arriving simultaneously. There is considerable diversity amongst migrants in Ireland; the 2011 Census showed 199 countries of origin, the most common of which were Poland, the United Kingdom, Lithuania, Latvia, and Nigeria. ${ }^{5}$ It is expected that Middle Eastern countries will rank higher in the 2016 Census figures because of the large efflux of refugees fleeing violence.

Both economic migrants and refugees have complex health needs including addressing infectious diseases, malnourishment, gender-specific issues, cultural adaptation, and mental health. While voluntary migrants may experience positive repercussions such as improved income or better employment opportunities in their new country, they are also frequently subject to racism, psychological stress, poor 
working conditions, and loss of family and social support. ${ }^{4}$ Guest workers residing temporarily in a country are often precluded from forming stable long-term relationships. This is related to increased numbers of casual and commercial sex contacts, which markedly increases the risk of sexually transmitted infections (STIs). ${ }^{6}$ Economic migrants often face precarious and exploitative working conditions which increase their susceptibility and exposure to ill health. ${ }^{4}$ Legislative protections for economic migrants and guest workers are required to safeguard their rights and health.

Refugees often face immiseration, marginalization, unstable housing situations, loss of family and support networks, and discrimination in addition to their resultant health consequences. Refugees displaced due to armed conflict suffer among the worst mix of unhealthy societal determinants and associated health conditions. ${ }^{4}$ While the current mass movement of refugees has created the conditions for potential xenophobia and has prompted calls for restricting borders, ${ }^{3}$ it should be noted that Ireland had an estimated net migration flow of -11600 in $2015 .^{7}$

Migrants can experience serious health consequences, including high rates of infectious disease and malnutrition. ${ }^{4}$ Several factors influence the incidence of infectious diseases among migrants, including exposure in the native country or on the migration route and the reality of life in the adopted country. ${ }^{8}$ The recommended assessment program for migrants in Ireland includes varicella zoster virus, hepatitis B, hepatitis $\mathrm{C}, \mathrm{HIV}$, intestinal parasites, malaria, measles, polio, rubella, STIs, and tuberculosis (TB). ${ }^{5}$ Health care workers (HCWs) must remember their responsibility to notify their area's Director of Public Health of not only listed notifiable diseases, but also any clusters of presentations. ${ }^{9}$

The majority of cases of malaria, TB, and enteric fever are diagnosed in the migrant community. ${ }^{8} \mathrm{~TB}, \mathrm{HIV}$, and enteric fever are communicable diseases, which makes the rapid screening of migrants upon arrival to Ireland an important matter of concern for public health officials. The unregulated use of anti-TB drugs in many countries has led to the emergence of multi drug-resistant TB (MDRTB) strains. ${ }^{4}$ MDRTB is difficult to treat and is associated with a high case-fatality rate if untreated ${ }^{10} ; 86 \%$ of cases of MDRTB occur in migrants. Migrants account for the majority of heterosexual HIV diagnoses. ${ }^{8}$ All sexually active migrants from countries with an HIV rate $>1 \%$ should be offered a full sexual health assessment. ${ }^{5} \mathrm{HCW}$ can play a role in reducing further transmission of HIV by promoting health literacy and countering misinformation, for example, the high-profile denial that HIV is the cause of AIDS. ${ }^{6}$ There can be significant cultural barriers to seeking treatment for HIV which contribute to late diagnoses being more likely in migrants. ${ }^{8}$ Country of origin is an important consideration; clinical suspicion of TB should be higher in migrants from the Indian subcontinent, and of HIV in migrants from Sub-Saharan Africa. ${ }^{8}$ While migrants comprise the vast majority (70\%$88 \%$ ) of malaria cases, the Health Protection Surveillance Centre (HPSC) recommends that only symptomatic migrants should be offered testing. ${ }^{5,8} 62 \%-65 \%$ of enteric fever diagnoses occur in migrants. Migrants who return to their home countries to visit their friends and family are the main at-risk group of travellers for contracting malaria and enteric fever. ${ }^{8}$ These patients should be advised on chemoprophylaxis for malaria and vaccination against typhoid. TB, HIV, malaria, and enteric fever may present in non-specific ways initially. It is important that HCWs, particularly in primary care, consider these diseases in the differential diagnosis for atrisk migrant patients presenting with suggestive symptoms. ${ }^{8}$ HPSC recommends that new migrants should be assumed unimmunized in the absence of information/documentation to the contrary. Children and adults should immediately begin a "catch-up" immunization schedule. ${ }^{5}$ When children are back on schedule, they can resume routine scheduled vaccines.

Migrants are at risk of malnutrition, which can manifest itself in many ways, including through skin problems, poor vision, anaemia, tinnitus, and joint pain. ${ }^{11}$ Migrants who have dealt with chronically low levels of nutrition are at increased risk of obesity and glucose intolerance and their associated health risks following migration to a richer country. ${ }^{6}$ In addressing malnutrition in migrants, a societal determinants of health approach is a necessary counterpart to the biomedical approach. Hunger and malnutrition cannot be addressed exclusively through clinical approaches; the structural factors of food and distribution must be addressed at a societal and political level. ${ }^{4}$

While all refugees are highly vulnerable to physical trauma and illness, this vulnerability is heightened for women and children. The most vulnerable are unaccompanied children, who have been separated from their parents during the process of war or refugee flight. ${ }^{4}$ Family reunification is essential in minimizing these harms. In Irish law, under Section 18 of the Refugee Act, 1996, refugees under the age of 18 can apply for their parents to join them in Ireland.

Women now form a small majority (51.3\%) of international migrants resident in Ireland. ${ }^{1}$ This population has specific needs and concerns. Many female migrants have been victims of physical or sexual violence. A significant proportion of children involved with armed groups globally are girls. They have usually been abducted from their families and often have been subjected to years of sexual violence, abuse, and unwanted pregnancy. ${ }^{4}$ The education of women and girls is not valued in the country of origin of many migrants. A lack of education exacerbates the vulnerability of a female migrant. ${ }^{6}$ This may affect the utilization of health services and communications between HCWs and female patients. ${ }^{12}$

The number of female genital mutilation (FGM) survivors living in Ireland was estimated from 2011 Census statistics to be 3780 . As migration to Ireland from FGM-practising countries is an increasing trend, it is likely that this number is now higher than the estimates from the 2011 Census. FGM has many long-term sequelae including dyspareunia, menstrual problems, psychological trauma, and obstetric complications. ${ }^{13}$ Therefore, it is vital that HCWs - especially general practitioners (GPs) and obstetricians - inquire about FGM, particularly in patients who come from countries where FGM is widely practised such as Djibouti, Egypt, Guinea, Mali, Sierra Leone, Somalia, and Northern Sudan. It is essential that HCWs are aware of the prevalence of FGM among migrants in Ireland. They must be able to provide appropriate medical 
care to them and refer FGM survivors to the support services available through AkiDwA - an advocacy group representing African and migrant women in Ireland - and the specialised FGM survivor clinic in Dublin. HCWs should be aware that migrant families may travel to their home country to have FGM carried out on their daughters, which is an offense under the Criminal Justice (Female Genital Mutilation) Act, 2012.

Refugees who have been resettled in Western countries are approximately ten times more likely to suffer post-traumatic stress disorder (PTSD) than age-matched populations in those countries. ${ }^{14}$ Language and cultural differences can make these patients difficult to treat. Cross-cultural psychiatry is now a growth area in Western countries. One helpful solution is the use of cross-cultural diagnostic tools, such as the Harvard Trauma Questionnaire, a simple and reliable screening instrument for PTSD that is well received by refugee patients and staff. ${ }^{15}$

Cultural beliefs influence the ways in which health and illness are defined and understood, what actions may be taken to prevent or treat illness, and which healing authorities to consult. Anthropologists can be helpful in ascertaining how health programs and policies can be more effective or acceptable in particular contexts. For example, there may be value in integrating traditional medicinal practices in health campaigns or in highlighting protective aspects of certain cultural values, such as cooperativism. ${ }^{4}$ Individuals who are members of a cultural group in contact with another group (such as migrants interacting with the dominant group in the destination country) will experience various psychological changes, referred to as psychological acculturation. The melding of cultures can erase the distinction between groups, resulting in integration assimilation. ${ }^{16}$ This can sometimes be perceived as cultural demise, which may lead migrants to experience cultural bereavement. ${ }^{6}$ Cultural bereavement can be viewed as an adjusted response and inevitable consequence of migration. However, if symptoms are persistent or a cause of significant psychological distress, psychiatric intervention may be indicated. Dr. Maurice Eisenbruch has developed a framework for the identification of cultural bereavement in refugees which takes into account the language and cultural constructs of the bereaved individual. ${ }^{17}$

Linguistically and culturally accessible care for migrants is essential in developing trust in and respect for Western medicine. ${ }^{18}$ There are now many modern solutions to this challenge. The advent of mobile technology provides several aids to patient-HCW communication, with many medical translation apps now available which provide comprehensive translations in a wide variety of languages. While some brochures from the Health Service Executive are available in a small number of languages, there is a lack of diagnostic tools available in the languages most commonly spoken by migrants - Polish, French, and Lithuanian. ${ }^{19}$ Here, there is a scope for adapting solutions initially created for Irish language speakers. For example, a geriatrician developed a Mini Mental State Exam in the Irish language for use in Galway University Hospitals. ${ }^{20}$ Providing linguistically accessible care can reduce possible errors which negatively impact migrants' health, such as patients' non-compliance due to incomprehension of instructions. $^{18}$

\section{Conclusion}

Migrant groups in Ireland are a diverse population with varied health needs. If the rights and health of migrants are to be effectively protected in Ireland, it is vital that health policies are based on data and research findings, not personal preferences, prejudices, or political pressure. Integration of migrants and multiculturalism as a national policy has many benefits for the health of migrants and society at large.

\section{Authors' Contributions}

All authors contributed significantly towards the study.

\section{Conflict of Interest Disclosures}

None declared.

\section{Ethical Approval}

Not applicable.

\section{Funding/Support}

This research was supported by Travel Medicine Society of Ireland.

\section{References}

1. United Nations Department of Economic and Social Affairs Population Division. International Migration 2015. New York: United Nations; 2015.

2. International Migration 2013 (wall chart). UNFPA - United Nations Population Fund website. http://www.unfpa.org/resources/ international-migration-2013-wall-chart. Accessed December 28, 2015. Published 2015.

3. Migration. UNFPA - United Nations Population Fund UNFPA website. http://www.unfpa.org/migration. Accessed December 28, 2015. Published 2015.

4. Birn A, Pillay Y, Holtz T, Basch P. Textbook of International Health. New York: Oxford University Press; 2009.

5. Infectious Disease Assessment for Migrants. 2nd ed. Dublin: Health Protection Surveillance Centre; 2015. https://www.hpsc. ie/A-Z/SpecificPopulations/Migrants/Guidance/File,14742,en.pdf. Accessed December 28, 2015.

6. Marmot M, Wilkinson R. Social Determinants of Health. Oxford: Oxford University Press; 2006.

7. Population and Migration Estimates April 2015. CSO - Central Statistics Office website. http://www.cso.ie/en/releasesandpublications/ er/pme/populationandmigrationestimatesapril2015/. Accessed December 28, 2015. Published 2015.

8. Wagner KS, Lawrence J, Anderson L, et al. Migrant health and infectious diseases in the UK: findings from the last 10 years of surveillance. J Public Health (Oxf). 2014;36(1):28-35. doi:10.1093/ pubmed/fdt021.

9. Notifiable Diseases. Health Protection Surveillance Centre (hpsc) website. http://www.hpsc.ie/NotifiableDiseases/. Accessed December 28, 2015. Published 2015.

10. Farmer P. Pathologies of Power. Berkeley: University of California Press; 2003.

11. Causes of malnutrition. Health Service Executive website. http:// www.hse.ie/eng/health/az/M/Malnutrition/Causes-of-malnutrition. html. Accessed December 28, 2015. Published 2015.

12. Walt G. Health Policy. Johannesburg: Witwatersrand University Press; 1994

13. RCSI, HSE, AkiDwA. Female Genital Mutilation: Information for Health-Care Professionals Working in Ireland. 2nd ed. Dublin: AkiDwA; 2013.

14. Fazel M, Wheeler J, Danesh J. Prevalence of serious mental disorder in 7000 refugees resettled in western countries: a systematic review. Lancet. 2005;365(9467):1309-1314. doi:10.1016/S01406736(05)61027-6. 
15. Mollica RF, Caspi-Yavin Y, Bollini P, Truong T, Tor S, Lavelle J. The Harvard Trauma Questionnaire. Validating a cross-cultural instrument for measuring torture, trauma, and posttraumatic stress disorder in Indochinese refugees. J Nerv Ment Dis. 1992;180(2):111-116.

16. Berry J. A psychology of immigration. J Soc Issues. 2001;57(3):615631. doi:10.1111/0022-4537.00231.

17. Bhugra D, Becker M. Migration, cultural bereavement and cultural identity. World Psychiatry. 2005;4(1):18-24.

18. Burgess A. Health challenges for refugees and immigrants. Refugee Reports. 2004;25(2). http://reliefweb.int/sites/reliefweb. int/files/resources/ACB7A9B4B95ED39A8525723D006D6047- irsa-refugee-health-apr04.pdf.

19. Population Usually Resident and Present in the State who Speak a Language other than English or Irish at Home by Birthplace, Language Spoken, Age Group and Census Year. StatBank - data and statistics. CSO website. http://www.cso.ie/px/pxeirestat/ Statire/SelectVarVal/Define.asp? Maintable=CDD46\&Plangua ge $=0$. Accessed December 28, 2015. Published 2015.

20. Ní Chaoimh D, De Bhaldraithe S, O’Malley G, Mac Aodh Bhuí C, O'Keeffe ST. Importance of different language versions of cognitive screening tests: Comparison of Irish and English versions of the MMSE in bilingual Irish patients. Eur Geriatr Med. 2015;6(6):551553. doi:10.1016/j.eurger.2015.10.006. 